\title{
Aspectos histopatológicos da adenomiose em úteros bovinos nas diferentes fases do ciclo estral
}

[Histophatological aspects of adenomyosis in bovine uteri in different phases of the estrous cycle]

\author{
L. Moreira, E.C.Q. Carvalho, M.C. Caldas-Bussiere \\ Centro de Ciências Agrárias e Tecnologias Agropecuárias - UENF \\ Av. Alberto Lamego, 2000 \\ 28013-602 - Campos dos Goytacazes, RJ
}

\begin{abstract}
RESUMO
Relacionaram-se as características da adenomiose com as fases do ciclo estral em 61 peças de úteros de bovinos colhidas em matadouros. A adenomiose foi classificada em superficial e profunda. A fase do ciclo estral foi estimada pela morfologia, pela coloração e pela vascularização do corpo lúteo e presença ou não de folículos ovarianos maiores que $8 \mathrm{~mm}$. Os animais que estavam em anestro $(\mathrm{n}=11)$ apresentaram a menor ocorrência de adenomiose $(8,2 \%)$, e os que estavam na fase lútea média $(n=21)$, a maior $(31,0 \%)$. Nas fases lútea inicial $(\mathrm{n}=13)$ e folicular $(\mathrm{n}=16)$ as ocorrências foram semelhantes, $18,0 \mathrm{e}$ $22,9 \%$, respectivamente. A maior porcentagem de adenomiose profunda ocorreu nas fases lútea inicial e média, 45,0 e 47,4\%, respectivamente, e durante o anestro e a fase folicular foram de 20,0 e $14,3 \%$, respectivamente. Os resultados sugerem que a fase do ciclo estral influencia na ocorrência de adenomiose e no grau de infiltração miometrial das glândulas endometriais.
\end{abstract}

Palavras-chave: bovino, adenomiose, ciclo estral, histopatologia

\begin{abstract}
The relationship of the adenomyosis characteristics and the phases of the estrus cycle in 61 cows bovine's uteruses collected in slaughterhouses was studied. The adenomyoses were classified as superficial and deep. The morphology, staining and vascularization of the corpus luteum and the presence or not of larger ovarian follicles than $8 \mathrm{~mm}$ helped to estimate the estrus cycle. The cows in anestrus $(n=11)$ showed the least occurrence of adenomyosis $(8.2 \%)$ and the animals in the medium luteal phase $(n=21)$ the largest one $(31,0 \%)$. In the initial luteal phase $(n=13)$ and the follicular phase $(n=16)$ the occurrences of adenomyosis were similar and equals to 18.0 and $22.9 \%$, respectively. The largests percentage of deep adenomyosis were found in the initial and in the medium luteal phases, 45.0 and $47.4 \%$, respectively, and during the anestrus and the follicular phase they were 20.0 and $14.3 \%$, respectively. The data suggest that the cycle phase influences in adenomyosis occurrence and in the degree of miometrial infiltration of the endometrial glands.
\end{abstract}

Keywords: bovine, adenomyosis, estrous cycle, histopathology

\section{INTRODUÇÃO}

A adenomiose uterina é caracterizada pela localização distópica de glândulas e estroma endometrial por entre os feixes musculares do miométrio (Jubb e Kennedy, 1987; Moreira et al., 2006), sendo considerada um crescimento celular benigno e relativamente incomum em fêmeas domésticas. De acordo com a literatura, a adenomiose é um achado ocasional em vacas, como parte de um desarranjo local na aplasia segmentar, ou pela má formação de uma das extremidades dos cornos uterinos (Jubb e Kennedy, 1987). 
Estudos sugerem que essa enfermidade seja causada, primariamente, pela desestruturação da borda endométrio-miometrial, que consiste em uma matriz extracelular (MEC) especializada que separa as camadas uterinas, mantendo-as compartimentalizadas. Sua integridade é mantida pela ação conjunta das colagenases e seus inibidores, por sua vez, são modulados pelos hormônios reprodutivos, citocinas e fatores de crescimento localmente produzidos em humanos e animais (Matsuda et al., 2001; Curry e Osteen, 2003). Assim, alterações no perfil hormonal, estrógenos, progestágenos e prolactina, poderão culminar com uma invasão da camada muscular pelos componentes endometriais - células do estroma e glândulas endometriais (Levgur et al., 2000; Mori et al., 2000).

Atribui-se a essa enfermidade interferência na sobrevivência espermática e embrionária, e na implantação do embrião, em função de alterações vasculares (Levgur et al., 2000), de estresse oxidativo (Ota et al., 1998) e de degradação excessiva da MEC (Mori et al., 2000), com modificações no microambiente uterino, que culmina com subfertilidade e infertilidade em mulheres e em animais de laboratório (Mori et al., 2000; Inagaki et al., 2003).

Diante da escassez de informação e de diagnóstico da adenomiose em fêmeas bovinas, este trabalho teve os objetivos de identificar e classificar a adenomiose de fêmeas bovinas não prenhes e relacioná-la com a fase do ciclo estral.

\section{MATERIAL E MÉTODOS}

Foram colhidas 61 genitálias e gônadas, individualmente protocoladas, de fêmeas bovinas azebuadas, não prenhes, em idade reprodutiva, abatidas em matadouros frigoríficos estaduais, do município de Campos dos Goytacazes, RJ, entre março de 2003 e dezembro de 2004.

A fase do ciclo estral foi estimada no momento da colheita por meio das características morfológicas do corpo lúteo, de acordo com Pavlock et al. (1992). As peças eram armazenadas em recipientes térmicos refrigerados e remetidas ao laboratório. Uma amostra de $5 \mathrm{~cm}$ de comprimento e $3 \mathrm{~cm}$ de largura, retirada do terço medial de um dos cornos uterinos e aberta com a superfície serosa voltada para um papel filtro, para evitar o seu dobramento, era fixada em formalina neutra tamponada a $10 \%$ e, após um período mínimo de 48 horas, era processada por inclusão em parafina, cortada a $5 \mu$ e corada pelos métodos hematoxilina e eosina, tricromático de Gomori e van-Gieson.

Para auxiliar a determinação da intensidade de penetração de tecido endometrial por entre as fibras miometriais, era utilizado o método classificatório recomendado por Moreira et al. (2006), que obedeceu ao grau de infiltração do foco glandular no miométrio em: a) superficial quando a insinuação glandular não ia além do miométrio superficial, na profundidade correspondente ao diâmetro de uma a três unidades glandulares, e b) profunda - quando a insinuação glandular ultrapassava o miométrio superficial, na profundidade correspondente ao diâmetro de mais de três unidades glandulares.

Para a análise da ocorrência, classificação da adenomiose e a fase do ciclo estral foi utilizado o teste do qui-quadrado diferenciado (Kruskal Wallis) com $\alpha$ de 0,05 , pelo procedimento FREQ/CHISQ do SAS.

\section{RESULTADOS}

Oito peças uterinas exibiram projeções nodulares na superfície serosa (Fig. 1A) que, ao corte longitudinal, revelaram espessamento da parede do útero (Fig. 1B), que estava acometido por adenomiose profunda, confirmada pela histopatologia (Fig. 1C).

Pela coloração de van-Gilson, evidenciou-se acentuada proliferação de colágeno, provavelmente proveniente do endométrio (estroma endometrial), acompanhando as glândulas infiltradas no miométrio (Fig. 1A, E e F).

Foram diagnosticados $49 \quad(80,3 \%)$ casos de adenomiose. A maior freqüência ocorreu na fase lútea média (Tab. 1) e não se observou diferença acentuada na freqüência de adenomiose entre as fases folicular e lútea inicial. Outras relações entre o número de animais estudados, a fase do ciclo estral e a ocorrência de adenomiose, e entre a fase do ciclo estral e o tipo de adenomiose (superficial ou profunda) são apresentadas ou podem ser calculadas a partir dos resultados encontrados na Tab. 1 e na Fig. 2. 


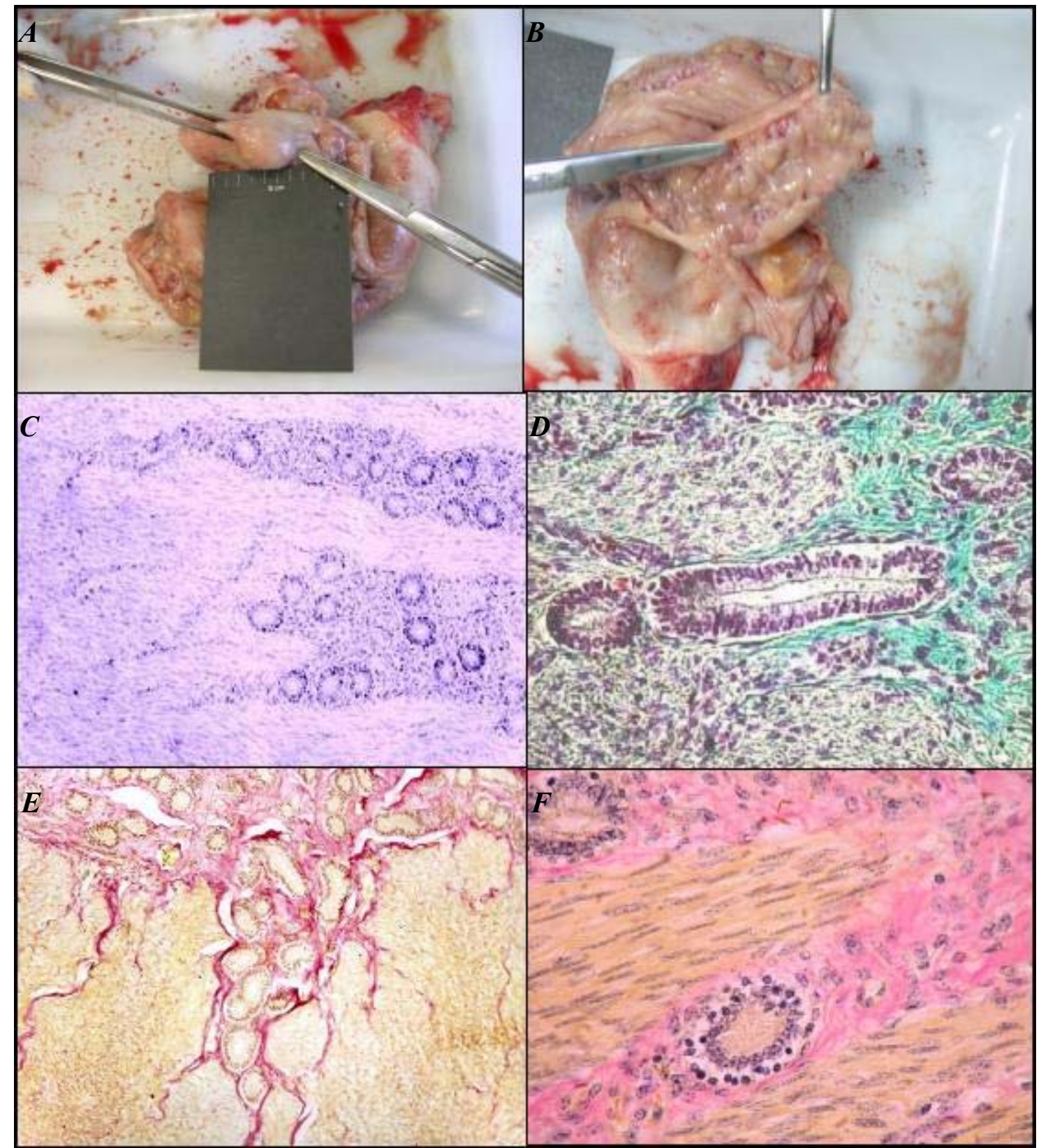

Figura 1. Útero de vaca. Adenomiose. A) Nódulo uterino, projetado contra o perimétrio. B) Corte longitudinal do corno uterino, mostrando espessamento da parede. C) Glândulas e estroma endometrial imersas no miométrio profundo; Obj.10x; HE. D) Colágeno (verde) acompanhando as unidades glandulares imersas em miométrio superficial; Obj. 40x; tricromático de Gomori. E e F) Glândulas endometriais imersas em miométrio; Obj. 10x e 40x, respectivamente, van-Gieson; note as fibras colágenas coradas em vermelho e fibras musculares em amarelo. 
Tabela 1. Frequência de adenomiose segundo o ciclo estral em fêmeas bovinas abatidas em matadouros

\begin{tabular}{lccc}
\hline \multicolumn{1}{c}{ Fase do ciclo estral } & \multicolumn{2}{c}{ Com adenomiose $(\%)$} & \multirow{2}{*}{$\begin{array}{c}\text { Sem adenomiose } \\
(\%)\end{array}$} \\
\cline { 2 - 3 } & Superficial & Profunda & $54,6(6 / 11)$ \\
Anestro & $36,4(4 / 11)$ & $9,1(1 / 11)$ & \\
Folicular & $75,0(12 / 16)$ & $12,5(2 / 16)$ & $12,5(2 / 16)$ \\
Lútea inicial & $46,2(6 / 13)$ & $38,5(5 / 13)$ & $15,4(2 / 13)$ \\
Lútea média & $47,6(10 / 21)$ & $42,9(9 / 21)$ & $9,4(2 / 21)$ \\
\hline
\end{tabular}

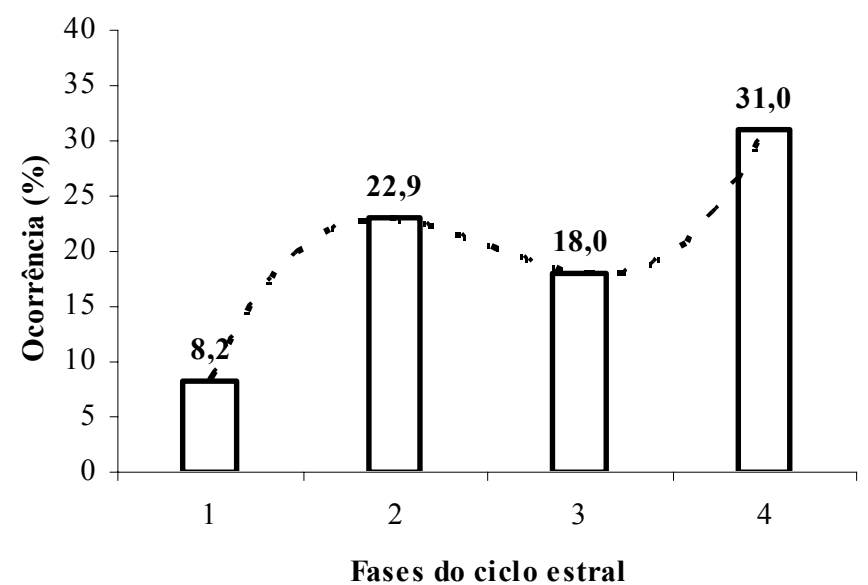

\section{$\underline{\text { Legenda }}$}

1. Anestro

2. Fase folicular

3. Fase lútea inicial

4. Fase lútea média

Figura 2. Porcentagem de ocorrência de adenomiose de acordo com a fase do ciclo estral de fêmeas bovinas abatidas em matadouros.

\section{DISCUSSÃO}

$\mathrm{Na}$ pecuária de corte, fêmeas que apresentam baixa eficiência reprodutiva geralmente são descartadas sem que se tenha uma análise mais detalhada do seu histórico reprodutivo. Isso pode estar associado a muitos fatores, como o não diagnóstico de alguma afecção reprodutiva, infecções associadas ao trato reprodutivo, má qualidade do sêmen e falhas de manejo, em geral, que resultam na eliminação de indivíduos de alto potencial genético. O resultado de $80,3 \%$ de adenomiose em úteros bovinos é uma evidência de que se deve dar maior importância a essa enfermidade que, apesar da dificuldade de diagnóstico, poderia ser apontada como um dos motivos de descarte de animais em idade reprodutiva.

A adenomiose severa resulta em um aumento de volume do útero, atribuído à hipertrofia e hiperplasia da musculatura uterina adjacente ao foco adenomiótico em camundongas (Mori et al., 1981) e mulheres (Parrot et al., 2001). O aumento do volume uterino encontrado neste estudo (Fig. 1A e B) pode ser explicado pelo distúrbio do crescimento da musculatura lisa em úteros acometidos por adenomiose, aspecto já relatado pelos autores citados. Nenhuma análise morfométrica, no entanto, foi realizada nesta investigação.

Segundo Matsuda et al. (2001) e Custis et al. (2002), a migração de tecido endometrial dá-se ao longo do trajeto dos vasos sangüíneos, com comprometimento da MEC da borda endométriomiometrial e da membrana basal dos vasos e das glândulas endometriais que participam do processo, explicando a desorganização e a invasão do colágeno endometrial no miométrio observados neste experimento (Fig. 1E). Segundo Curry e Osteen (2003), as colagenases dão suporte à invasão do miométrio devido à degradação direta da MEC e pela indução de fatores de crescimento liberados pelas membranas basais degradadas por essas proteinases, que estão elevadas nessa enfermidade em camundongas (Mori et al., 2000) e em humanos (Inagaki et al., 2003).

A administração crônica de estrógenos induz adenomiose uterina em humanos e animais (Hart, 1990). O tecido acometido por essa desordem do crescimento celular sintetiza estrógenos e seus 
receptores, portanto é classificada como estrógeno-dependente (Kitawaki et al., 2003). No entanto, para que ocorra o desenvolvimento da doença, é necessário que haja o sincronismo entre estrógenos e progesterona, ou seja, que exista sensibilização do endométrio por esses esteróides (Mori et al., 1981).

A menor freqüência de adenomiose das vacas em anestro, provavelmente, ocorreu em razão da baixa concentração de estrógenos e progesterona. À medida que a concentração desses esteróides se elevou, a ocorrência da desordem aumentou, seguindo um padrão cíclico mostrado pela regressão linear (Fig. 2).

A fase folicular, que apresentou a maior ocorrência de adenomiose superficial $(75,0 \%)$, onde o grau de infiltração não ultrapassou o miométrio superficial, permitiu sugerir que esse estádio do ciclo estral seja um ponto de retorno (proliferação), isto é, que há regressão da lesão em alguns animais quando o estímulo estrogênico cessa, principalmente das glândulas basilares.

A fase lútea, que exibiu a maior ocorrência de adenomiose $(49,0 \%)$, mais elevada na fase lútea média $(31,0 \%)$, sugere que há alguma influência da progesterona na progressão da doença.

De acordo com Mori et al. (1981), é necessária a administração de estrógeno e de progesterona conjuntamente para indução de adenomiose em camundongas ovariectomizadas. Assim, propõese classificar a adenomiose como enfermidade esteróide-dependente. No entanto, essa desordem tem os estrógenos como fator desencadeador, proliferando em uma fase estrógeno-dependente e, provavelmente, seja mantida e amplificada na fase lútea, em que a progesterona é o principal hormônio secretado pelos ovários. Os resultados encontrados neste estudo confirmam os já observados em mulheres e camundongas. Ainda, a utilização de antiprogestinas foi capaz de promover a regressão da enfermidade em mulheres e animais, reforçando o papel fundamental da progesterona na manutenção da adenomiose (Singtripop et al., 1992; Mori et al., 2002; Wang et al., 2002).

É importante, portanto, que a fase do ciclo estral seja levada em consideração no momento da colheita de amostra uterina para diagnóstico da adenomiose em vacas, sendo $\mathrm{o}$ anestro $\mathrm{o}$ momento ideal para o diagnóstico, pois as concentrações dos esteróides ovarianos estão em níveis basais, não interferindo na apresentação da moléstia.

De acordo com a literatura consultada, a adenomiose é um achado ocasional em vacas como desordem congênita (Jubb e Kennedy, 1987) e, também, é encontrada em cadelas junto à hiperplasia endometrial cística (McEntee, 1990). A adenomiose uterina foi observada em novilhas/vacas abatidas em matadouros por Monteiro et al. (2003), que observaram ocorrência de 26,7\% (16/60) em Birigupi-SP, e por Moreira et al. (2006), 70,4\% (19/27). As porcentagens são conflitantes incluindo a deste estudo, contudo não se trata de um achado congênito e tão incomum em vacas, como relatado pela literatura.

A escassez de registros dessa distrofia nas fêmeas domésticas de interesse agropecuário talvez se justifique por ser uma lesão da túnica miometrial que, classicamente, não compõe as amostras para biopsia endometrial. Por se tratar de víscera sem nenhum valor comercial, existe pouco interesse pelas peças (genitálias femininas), que são descartadas nos matadouros.

A presente investigação da adenomiose uterina em vacas mostrou grande similaridade com a adenomiose em úteros de mulheres, o que permite sugerir mecanismos de formação semelhantes. Além disso, este estudo dá suporte à idéia de que a prolongada estimulação hormonal de glândulas basais no início do processo de formação desse distúrbio permite a proliferação e invasão miometrial.

Conclui-se que o número de casos de adenomiose foi elevado em vacas abatidas na Região Norte Fluminense e que a fase do ciclo estral, no momento da colheita uterina, influencia no grau de infiltração de tecido endometrial, ao mostrar um padrão de apresentação de acordo com a fase do ciclo estral (status hormonal) e exibir maior ocorrência na fase lútea.

\section{AGRADECIMENTOS}

Os autores agradecem à Prof ${ }^{\mathrm{a}}$ Célia Raquel Quirino pela realização da análise estatística, aos técnicos do SMAP e LMGA, aos Matadouros 
Estaduais de Campos dos Goytacazes, RJ, e à UENF-FAPERJ pelo financiamento desta investigação.

\section{REFERÊNCIAS BIBLIOGRÁFICAS}

CURRY, T.; OSTEEN, K. The matrix metaloproteinase system: changes, regulation, and impact throughout the ovarian and uterine reproductive cycle. Endocr. Rev., v.24, p.428$465,2003$.

CUSTIS, K.M.; HILLIS, S.; MARCHBANKS, P. Disruption of the endometrial-myometral border during pregnancy as a risk factor for adenomyosis. Am. J. Obstet. Gynecol., v.55, p.543-554, 2002

HART, J.E. Endocrine pathology of estrogens species differences. Pharmacol. Ther., v.47, p.203-218, 1990.

INAGAKI, N.; UNG, L.; OTANI, T. et al. Uterine cavity metalloproteinase and citokines in patients with leiomyoma, adenomyosis or endometrial polyp. Eur. J. Obstet. Gynecol. Reprod. Biol., v.4, p.1-7, 2003.

JUBB, K.V.; KENNEDY, P.C. The Female Genital System. In: Pathology of domestic animals. 4. ed. Saint Louis: Academic, 1987. p.377

KITAWAKI, J.; KADO, N.; ISHIHARA, H. Endometriosis: The pathophysiology as an estrogen-dependent disease. J. Steroid Biochem. Mol. Biol., v.83, p.149-155, 2003.

LEVGUR, M.; ABADL, M.A.; TUCKER, A. Adenomyosis: symptoms, histology and pregnancy terminations. Obstet. Gynecol., v.95, p.688-691, 2000.

MATSUDA, M.; SASABE, H.; ADACHI, Y. Increased invasion activity of endometrial stromal cells and elevated expression of matrix metallproteinase messenger RNA in the uterine tissues of mice experimentally induced adenomyosis. Gen. Obstet. Gynecol., v.185, p.1374-1380, 2001.

McENTEE, K. The uterus: atrophic, metaplastic and proliferative lesions. In: McENTEE, K. (Ed). Reproductive pathology of domestic mammals. San Diego: Academic, 1990. p.167190.
MONTEIRO, C.M.R.; FARIAS, E.C.; PERRI, S.H.V. et al. Estudo das características histológicas do útero e tubas uterinas de vacas e novilhas Nelore (Bos primigenius indicus). Braz. J. Vet. Res. Anim. Sci., v.40, p.5-19, 2003.

MOREIRA, L.; SILVEIRA, L.S.; LEMOS, L.S. et al. Histopatologia da adenomiose em vacas abatidas no Norte Fluminense. Cien. Anim. Bras., v.7, p.85-91, 2006.

MORI, T.; KURATA, Y.; TABATA, Y. Priming effects of novel nonsteroidal progesterone receptor modulators CP8816 and CP8863 on the development of adenomyosis in the mouse uterus. Life Sci., v.71, p.527-535, 2002.

MORI, T.; NAGASAWA, H.; TAKAHASHI, S. The induction of adenomyosis in mice by intrauterine pituitary isografts. Life Sci., v.29, p.1277-1282, 1981.

MORI, T.; YAMASAKI, S.; MASUI, F. et al. Supression of the the development of experimentally induced uterine adenomyosis by a novel matrix metalloproteinase inhibitor, ONO4817, in mice. Exp. Biol. Med., v.5, p.429-433, 2000.

OTA, H.; IGARASHI, S.; TANAKA, T. Endothelial nitric oxide synthase in the endometrium during the mestrual cycle in patients with endometriosis and adenomyosis. Fertil. Steril., v.69, p.165-172, 1998

PARROT, E.; BUTTERWORTH, M.; GREEN, A. et al. Adenomyosis - A result of disordered stromal differentiation. Am. J. Pathol., v.159, p.623-630, 2001.

PAVLOK, A.; LUCAS-HAHN, A.; NIEMANN, A. et al. Fertilization and developmental competence of bovine oocytes derived from different categories of antral follicles. Mol. Reprod. Dev., v.31, p.63-67, 1992.

SINGTRIPOP, T.; MORI, T.; SAKAMOTO, S. et al. Suppression of the development of uterine adenomyosis by danazol treatment in mice. Life Sci., v.51, p.1119-1125, 1992.

WANG, P.H.; YANG, T.S.; LEE, W.L. et al. Treatment of infertile women with adenomyosis with a conservative microsurgical technique and a gonadotropin-releasing hormone agonist. Fertil. Steril., v.73, p.1061-1072, 2002. 